\title{
Member list of issue group
}

\section{ACADEMIC ADVISERS}

Saskia Sassen (Professor, Columbia University)

Peter Taylor (Royal Academy of Social Science, Professor, University of Loughborough)

Chen Jiagui (Vice President of Chinese Academy of Social Sciences (CASS))

Fei Changhong (Director of Institute of Finance and Trade Economics of CASS)

Yang Yang (Director of International Cooperation Bureau of CASS)

\section{AUTHORS AND CONTRIBUTORS}

Pengfei Ni (Institute of Finance and Trade Economics, CASS)

Peter Karl Kresl (Bucknell University, USA)

Jianfa Shen (Geography and Resources Management Department, The Chinese University of Hong Kong)

Qinghu Hou (Center for Combinatorics, Nankai University, China)

Fengyong Lv (Institute of Finance and Trade Economics, CASS)

Jin Huang (School of Humanity and Economics of Beijing University of Posts and Telecommunications)

Xiaolan Yang (School of Humanity and Economics of Beijing University of Posts and Telecommunications)

Yue Zhang (Graduate School, Chinese Academy of Social Sciences)

\section{MEMBERS OF ACADEMIC COMMITTEE (COMMITTEE OF GLOBAL URBAN COMPETITIVENESS PROJECT)}

Peter Karl Kresl (President, Emeritus Professor, Bucknell University)

Sasaki Komei (Professor, Japan Northeastern University)

Pierre-Paul Proulx (Senior researcher, Canada Policy Research Institute)

William Fred Lever (Emeritus Professor, Department of Urban Studies at the University of Glasgow, UK)

Luis Jaime Sobrino Figueroa (Professor, Urban and Environmental Studies, The College of Mexico, Mexico)

Dong-Sung Cho (Professor, Strategy and International Business, Seoul National University, Korea)

Jianfa Shen (Professor, Geography and Resources Management Department, The Chinese University of Hong Kong) 
Francisco Antonio Serrano Camarena (Assistant Professor, Centre for the Development of International Business, The Technological Institute of Monterrey: Chihuahua, Mexico)

Leo van den Berg (Professor of Regional and Urban Economics, Erasmus University Rotterdam, Netherlands)

Jedo Felaly (Professor, University of Florence, Italy)

Sajeo Kangte (Professor, Economy and Geography Department of University of Turin)

Dela Hansenpulage (Professor, Europe Urban Academy of Wismar University, Germany)

Pengfei Ni (Professor, Institute of Finance and Trade Economics, CASS)

\section{RESEARCH MEMBERS}

Yue Zhang (Graduate School, Chinese Academy of Social Sciences)

Zizhong Wang (Graduate School, Chinese Academy of Social Sciences)

Jie Gao (School of Economics of Wuhan University of Technology, China)

Xuemei Jiang (Institute of Finance and Trade Economics, Chinese Academy of Social Sciences)

Houming Zhang (Renmin University of China)

Zhiqiang Wang (Institute of Geographic Sciences and Natural Resources Research, Chinese Academy of Sciences)

Wu Zhang (Graduate School, Chinese Academy of Social Sciences)

Sun Chengping (Institute of Industry Economics, Chinese Academy of Social Sciences)

\section{ACADEMIC ASSISTANTS}

Jin Huang (School of Humanity and Economics of Beijing University of Posts and Telecommunications)

Yang Xiaolan (School of Humanity and Economics of Beijing University of Posts and Telecommunications)

Wang Zizhong (Graduate School, Chinese Academy of Social Sciences)

\section{MEMBERS OF DATA COLLECTION (IN RANDOM ORDER)}

Xiaoting Wang (Peking University), Huirong Wu (Peking University), Hao Li (Peking University), Wei Chen (Peking University), Wenting Zeng (Peking University), Liwei Zhou (Peking University), Wen Xu (Peking University), Fanghua Zhang (Peking University), Jiangli Su (Beijing Foreign Studies University), Xuezhi Liu (Graduate School of CASS), Hua Chai (Graduate School of CASS), Feiran Guo (Graduate School of CASS), Mu Cheng (Graduate School of CASS), Sha Li (Graduate School of CASS), Xinhui Wu (Graduate School of CASS), Yanhong Huang (China University of Mining and Technology), Yan Wang (Beijing University of Technology), Congying Li 
(Nankai University), Yun Xu (Nankai University), Qin Wang (Dongbei University of Finance and Economics), Ke Xiao (Wuhan University of Technology), Haoqiang Wang (Henan University), Jianqiu Zhang (Henan University), Shen Zhiqun (Beijing Normal University), Kang Li (Party School of the Central Committee of CPC), Xiaoshuai Ye (Party School of the Central Committee of CPC), Mojia Gao (Beijing Technology and Business University), Lili Zhang (University of Science and Technology Beijing), Shanshan Zhao (University of Science and Technology Beijing), Ying Jiang (Renmin University of China), Xiaona Wang (Beijing Language and Culture University), Hui Wang (Beijing Language and Culture University), Wei Guo (Beijing Language and Culture University), Dewei Che (Beijing Language and Culture University), Rui Duan (Beijing Language and Culture University), Tao $\mathrm{Hu}$ (Beijing University of Posts and Telecommunications), Yuan Yuan (Beijing University of Posts and Telecommunications), Mingxin Chen (Beijing University of Posts and Telecommunications), Hengchang Cui (Beijing University of Posts and Telecommunications), Xu Cao (China Foreign Affairs University), Min Zhan (China Foreign Affairs University), Xue Li (China Foreign Affairs University), Xin Xie (China Foreign Affairs University), Lian Wang (China Foreign Affairs University), Keyun Liu (China Foreign Affairs University), Jin Jin (China Foreign Affairs University).

\section{ABOUT THE GUCP}

The Global Urban Competitiveness Project (GUCP) was initiated by Professor Peter Karl Kresl (Bucknell University, USA) and Professor Pengfei Ni (Chinese Academy of Social Sciences, China) during the first international forum on urban competitiveness in August 2004. The GUCP, which was founded in Ottawa in April 2005, is a sustainable project on global urban competitiveness. It aims to gather specialists and experts who are interested in urban competitiveness to conduct research. The GUCP has a committee, in which Professor Peter Karl Kresl is President and Professor Pengfei Ni is General Secretary. The Secretariat of the committee is situated at the Institute of Finance and Trade Economics (IFTE), Chinese Academy of Social Sciences (CASS) Beijing, China.

The aims of the GUCP are to:

1. analyze aspects of the competitiveness of the world's urban regions,

2. promote better communication among those who are doing research on urban competitiveness,

3. enhance contact between researchers and practitioners in urban governance and leadership positions,

4. encourage more effective economic strategic planning in cities throughout the world,

5. help to make municipal leaders more able to enhance the competitiveness of their regions and thereby to improve the economic futures of the residents of these regions, and

6. increase the interest in and research in urban competitiveness on the part of researchers in both industrialized and developing economies. 
To achieve these aims the GUCP engages in:

1. in-depth academic research on urban competitiveness, holding one or more international conferences each year on the general topic of urban competitiveness,

2. policy research and policy briefing workshops from a global perspective that contributes constructively to urban government policy deliberations, and

3. executive training and research program for urban government in both industrialized and developing economies.

The Secretariat of GUCP is situated at the Institute of Finance and Trade Economics, CASS. Its mailing address is:

Global Urban Competitiveness Project

The Institute of Finance and Trade Economics (IFTE)

Chinese Academy of Social Sciences (CASS)

Room 2351, No. 2, Yuetan Beixiaojie, Beijing, China.

Tel: 86-10-68063478

Email: zgcsjzl@163.com

Website: www.gucp.org 